\section{Biodistribution Study of Pegylated Ppi Dendrimer Loaded with Prednisolone for Prolonged Release}

\section{Abstract}

PEGylated PPI dendritic scaffold was used for the delivery of an anti-leukemic drug, Prednisolone. The current study evolves and emerges the use PEGylated poly dendritic scaffold for the delivery of this drug. In this the prednisolone was loaded and synthesized with PEGylated PPI dendritic scaffold. Estimated the biodistribution of prednisolone in different vital organ was carriedout by HPLC method and the study was promising the distribution of drug candidate.

Keywords: PEGylated dendrimers; Prednisolone; Biodistribution

\section{Ramadoss Karthikeyan ${ }^{1}$, Sai Koushik $\mathrm{O}^{2}$, and Palanirajan Vijay RajKumar ${ }^{3}$}

1 Department of Biotechnology, Acharya Nagarjuna University, Nagarjuna Nagar, Guntur-522510, India

2 Department of Pharmaceutical Sciences, Vignan Pharmacy College, Vadlamudi-522213, India

3 UCSI University, Kualalampur, Malaysia

Corresponding author:

Ramadoss Karthikeyan

” rkcognosy@gmail.com

Department of Biotechnology, Acharya Nagarjuna University, Nagarjuna Nagar, Guntur-522510, India.

Tel: 91-9966847127

Citation: Karthikeyan R, Sai Koushik O, RajKumar PV. Biodistribution Study of Pegylated Ppi Dendrimer Loaded with Prednisolone for Prolonged Release. Nano Res Appl. 2016, 2:2.

Corticosteroids inhibit the inflammatory response to a variety of inciting agents and, it is presumed, slow healing. The current study aims at developing and exploring the use of PEGylated newer PPI dendrimers for delivery of anti-leukemic drug, Prednisolone.

Based on its anti-leukemic activity, short biological half-life and solubility characteristics, prednisolone was selected for incorporation into PEGylated ethylene diamine - PPI dendrimers. PEGylation of PPI dendrimers establishes PEGylated dendrimer as a suitable drug delivery system for Prednisolone. The hemolytic study of this delivery system could be safely administered through i.v. route. By delivering the drug for a prolonged period at a controlled rate, we expect that this approach will improve the management of drug therapy in leukemic patients.

\section{Materials and Methods}

\section{Materials}

PEG $_{4000}$, Reney Nickel was obtained from Sigma, Germany, Raney Nickel was procured from Merck pharmaceuticals private Ltd., 
Mumbai, India, Triethylamine, dioxan, ethylene diamine, N, N dicy-clohexylcarbodiimide (DCC), Cellulose dialysis bag MWCO 12-14 Kda, Himediaprivate Ltd., India, 4 dimethyl amino pyridine SD- fine chemicals private Ltd., Mumbai, India, Prednisolone was gifted from Shasunpharmaceuticalsprivate Ltd, Chennai, India.

\section{Synthesis of 5.0G PPI dendrimers}

Double Michael addiction reaction occurs between acrylonitrile and aqueous solution of ethylene diamine which leads to the half generation EDA-dendrimer-(CN) $4 n$ was synthesized. Next to the exothermic initial phase, the mixture was heated for $1 \mathrm{~h}$ at 80 ㅇ $\mathrm{C}$ to complete the addition reaction. By vacuum distillation, excess of acrylonitrile was removed. Later, use of Raney nickel as catalyst, the hydrogenation in methanol for $1 \mathrm{~h}$ at $70^{\circ} \mathrm{C}$ and $40 \mathrm{~atm}$ hydrogen pressures the EDA-dendrimer- $(\mathrm{NH} 2) 4 n$ of full generation was synthesized. Then the reaction mixture was cooled and filtered. Under reduced pressure the solvent was evaporated [7]. The product was then dried under vacuum. By repetition of all the above steps consecutively, EDA-PPI dendrimers up to 5.0G were prepared with acrylonitrile in increasing quantity [8]. The scheme of the synthesis is shown in Figure 1.

\section{Synthesis of PEGylated 5.0G PPI dendrimers}

To a solution of PEG $4000(0.32 \mathrm{mmol})$ in DMSO $(10 \mathrm{ml}), \mathrm{N}, \mathrm{N}$ dicyclohexylcarbodiimide (DCC) $(0.32 \mathrm{mmol})$ in DMSO $(10 \mathrm{ml})$ and 5G EDA-PPI dendrimer $(0.01 \mathrm{mmol})$ in dimethyl sulfoxide (DMSO) $(10 \mathrm{ml})$ were added together. At room temperature, the resultant solution was stirred for 5 days. By addition of water, the product was precipitated, dialyzed and filtered by MWCO 12-14 $\mathrm{Kda}$, Himedia, India. It was done against double distilled water for $24 \mathrm{~h}$ to remove free PEG 4000, DCC and partially PEGylated dendrimers.Laterthe lyophilization was done by Hetodrywinner, Germany [8]. The synthesis was shown in Figure 2.

\section{Drug Loading in PEGylated dendrimers}

PEGylated-PPI dendrimers of known molar concentrations (0.36:3.521, 0.36:7.042, 0.36:14.084 $\mathrm{g} / \mathrm{mole})$ of drug and

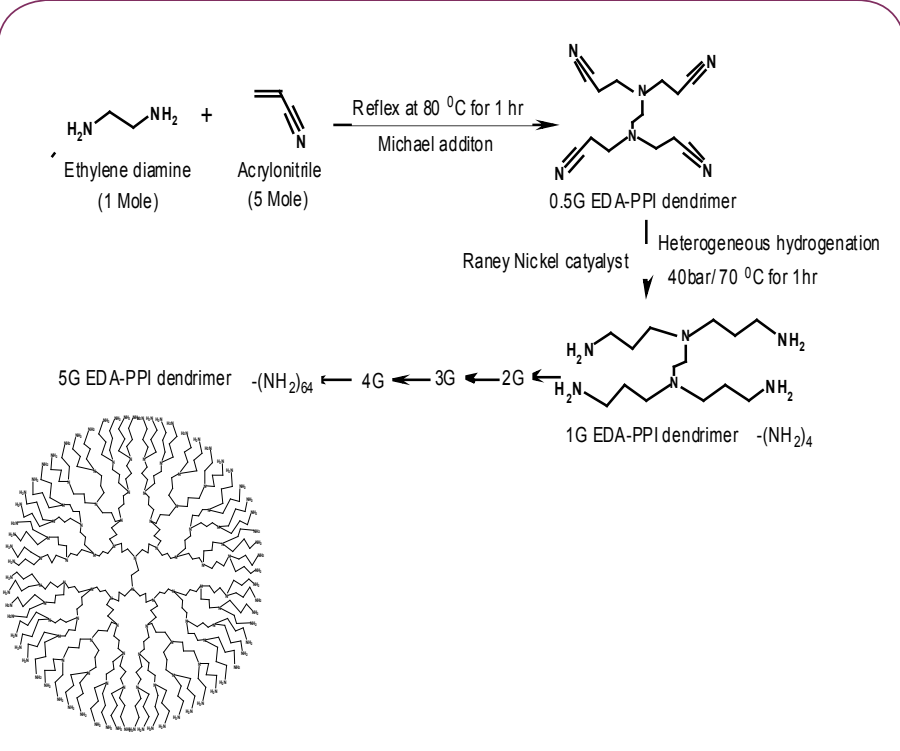

Figure 1 Schematic diagram for synthesis of PPI-5G dendrimer.

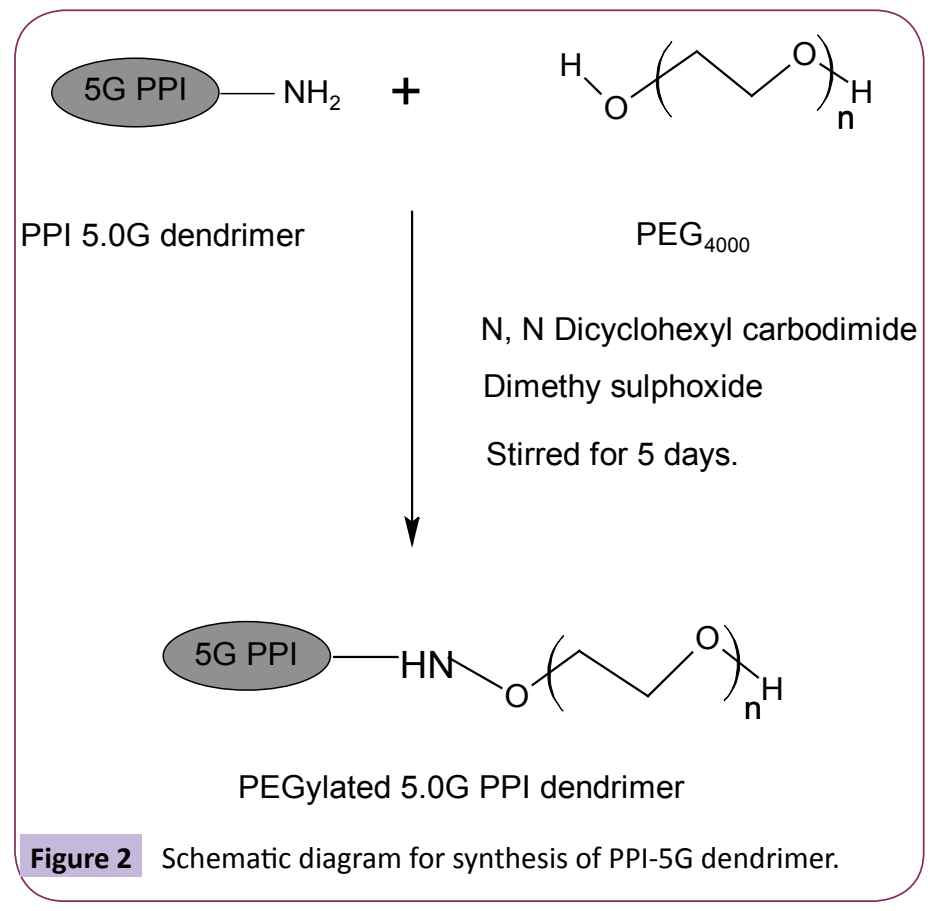

PEGylated polymer were dissolved separately in $100 \mathrm{ml}$ methanol respectively for the loading of each ratio of drug and polymer used. Next they were mixed with methanolic solution of Prednisolone. Using teflon beads the mixed solutions were incubated with slow magnetic stirring at $50 \mathrm{rpm}$ for $24 \mathrm{~h}$. These solutions were twice dialyzed in cellulose dialysis bag of MWCO 1000 Da Sigma, Germany. It was done against double distilled water under sink conditions for $10 \mathrm{~min}$ to remove free drug from the formulations. Later it was estimated spectrophotometrically at $\lambda$ max $248 \mathrm{~nm}$ by using UV-1601, Shimadzu, Japan to determine the amount of drug loaded within the system indirectly. The dialyzed formulations were lyophilized and used for further characterization.

\section{Biodistribution study}

To conduct the distributiobn study in rats the study was approved the proposal number (8/IAEC/VPC/Pharma/Res/20112012) by Institutional animal ethics committee (IAEC) under registration number of 1499/po/a/11/CPCSEA. Biodistribution studies of prednisolone loaded PEGylated dendrimer and plain prednisolone were performed in rats bearing with AML-193 leukemia .Prednisolone levels in the blood and various organs were estimated by HPLC method. Separation was carried out on reversed-phase C18 column (250 $4.6 \mathrm{~mm}, 5)$ and the column effluent was monitored by UV detector at $254 \mathrm{~nm}$. The mobile phase of methanol-glacial acetic acid-dichloromethane (1.5:8.0:90.5, v/v/v in Milli-Q water) was used at a flow rate was $1.8 \mathrm{~mL} / \mathrm{min}$ and the room temperature fluctuated from $15^{\circ} \mathrm{C}$ to $20^{\circ} \mathrm{C}$. The injection volume was $10 \mu \mathrm{L}$ [9].

\section{Statistical analysis}

The results are expressed as mean \pm standard deviation (S.D.) $(n=3)$ and statistical analysis was performed by Graph PadlnStat version 3.00 . 


\section{Results and Discussion}

\section{Synthesis and characterization PEGylated dendrimers}

FTIR and NMR spectroscopy: PPI 5.0G dendrimers were synthesized with slight modification of the procedure reported by Kumar et al., using ethylene diamine as initiator core. Synthesis of $0.5 \mathrm{G}$ PPI was confirmed by IR peaks, mainly of nitrile at 2248 $\mathrm{cm}^{-1}$. All the nitrile terminal 0.5G PPI got converted to $\left(\mathrm{NH}_{2}\right) 4$, which was confirmed by IR of PPI 1.0G that exhibited major peak at $3284.78 \mathrm{~cm}^{-1}$ for amine (N-H stretch). Likewise, IR peaks also confirmed the synthesis of PPI 5.0G dendrimers. The main peaks are of C-C bend $\left(1115.21 \mathrm{~cm}^{-1}\right)$; C-N stretch $\left(1243.44 \mathrm{~cm}^{-1}, 1374.50\right.$ $\left.\mathrm{cm}^{-1}\right) ; \mathrm{C}-\mathrm{H}$ bend $\left(1477 \mathrm{~cm}^{-1}\right) ; \mathrm{N}-\mathrm{H}$ deflection of amine (1665.40 $\left.\mathrm{cm}^{-1}\right)$ and primary amine at $3410 \mathrm{~cm}^{-1}(\mathrm{~N}-\mathrm{H}$ stretch), confirming that amine terminals were converted from nitrile terminal groups of dendrimer. The results matched with the reported synthesis of PPI dendrimers. The synthesized dendrimers were PEGylated using DCC and PEG 4000. IR and NMR data proved the synthesis of PEGylated dendrimers. The IR spectrum of PEGylated PPI 5.0G dendrimer exhibited major peak of $\mathrm{N}-\mathrm{H}$ stretch of amide at $3324.70 \mathrm{~cm}^{-1}$. An important IR peak at $1242.75 \mathrm{~cm}^{-1}$ of ether linkage (C-O) appears in the spectrum of PEGylated dendrimers. C-O stretch of amide group has been found near $1624.29 \mathrm{~cm}^{-}$ 1. The important peak of $\mathrm{C}-\mathrm{N}$ stretch of amide also appears at $2925.43 \mathrm{~cm}^{-1}$. NMR spectrum and shifts of PEGylated dendrimers as compared to that of simple dendrimers proved PEGylation. There was increase in integral value for the shift of secondary $-\mathrm{CH}_{2}$ groups on $\mathrm{PEGylation}$. This is due to the increase in number of secondary $-\mathrm{CH} 2$ groups in PEG that are linked on PEGylation. Similarly, strong peak of ether linkage appears at $3.507 \mathrm{ppm}$ due to the presence of ether linkages in PEG in high amount, remaining free amines $-\mathrm{CH}_{2}-\mathrm{NH}_{2}$ appears at3.341-3.410 ppm. The characteristic peak of amide linkage appeared near 2.504 ppm and $2.496 \mathrm{ppm}$ for carbonyl $-\mathrm{CH}_{2} \mathrm{C}=\mathrm{O}$ in NMR spectrum of PEGylated dendrimers.

\section{Drug loading in to the PEGylated dendrimers}

The known molar concentrations (1:0.5, 1:1, 1:2) of PEGylatedPPI dendrimers and drug Prednisolone, was used to load the drug in to PEGylated dendrimer system for getting optimized formulation. Dendrimeric terminal end groups [10], dendrimer generation [11], dendrimer concentration and $\mathrm{PH}$ [12]. Dendrimer based solubilization is due to hydrophilic-hydrophobic interaction, ionic interaction and encapsulation of hydrophobic drugsinto crevices of dendritic architecture. Non-covalent interactions between Prednisolone and PEGylated PPI 5.0G dendrimers, such as hydrophobic interaction and hydrogen bonding, contributed to the physical binding of drug molecules inside dendritic micelles and surface PEG layers. The percentage loading of both the drugs in PEGylated PPI 5.0G dendrimers was significantly increased in 1:1 ratio of dendrimer: drug for the formulation ( $p$ value 0.0001 , extremely significant) compared to 1:0.5 and 1:2 molar concentration of both the drugs respectively. PEGylation increases the Prednisolone loading capacity of the PPI 5.0G dendrimers due to more interaction of drug and PEG at the peripheral portions of dendrimers. Prednisolone entrapment in PEGylated dendrimers increased significantly due to more sealing of dendrimeric structure by PEG at the peripheral portions of dendrimers as coat, which prevented drug release by enhancing complexation probably by increasing steric hindrance over dendrimer periphery. Number of moles of the drug entrapped in $1 \mathrm{~mol}$ of PEGylated dendritic architecture was found to be in $1: 1$ ratio of dendrimers and drug is suitable as $89.20 \pm 0.2 \mathrm{~mol}$ for Prednisolone as compared to $7.28 \pm 1.9 \mathrm{~mol}$ in 1:0.5 molar concentration and $48.4 \pm 1.2$ molar concentrations in $1: 2$ ratio. If the drug entrapment is more than the required quantity leads to toxic to the host, increase in size leads to internal pressure were by leakage of drug from the system may happen. So the study considered to take up only the $1: 1$ ratio molar concentration followed in the preparation.

\section{Biodistribution of prednisolone from dendrimeric formulation}

In order to understand the fate of drug loaded PEGylated PPI 5.0 $\mathrm{G}$ dendrimers in vivo, the biodistribution to various major organs was investigated. The formulation $10 \mathrm{mg} / \mathrm{ml}$ was administered through oral rout for each animal in the group taken for the study. The amount of drug in the body depends upon its release, distribution, metabolism and excretion from the body. The biodistribution of prednisolone is generally more in bile and excretion is mainly through kidneys. However, due to sustained drug delivery and long circulatory nature, PEGylated PPI 5.0G dendrimers made the drug molecules more available in blood than in bile for longer period. The amount of plain drugs in different metabolic and excretory organ was found to be higher at $4^{\text {th }} \mathrm{hr}$ as compared to PEGylated dendrimer formulation, which indicated slow release pattern from the PEGylated dendritic formulations.

The amount of drug in the case of plain prednisolone was found to be $303 \pm 2.6 \mathrm{ng} / \mathrm{ml}$ in kidneys at $4^{\text {th }} \mathrm{hr}$, which was higher as compared to PEGylated dendritic formulation $(201 \pm 4.7 \mathrm{ng} / \mathrm{ml})$. The reversal of the position at the $8^{\text {th }} \mathrm{hr}$ indicated that most of the plain drug was eliminated out of the body [9]. In liver it was estimated that nearly $170 \pm 2.7 \mathrm{ng} / \mathrm{ml}$ than the free Prednisolone at $8^{\text {th }}$ hour. Parellely lung and spleen shows the drug absorption of 274 \pm 6.5 and $216 \pm 3.9 \mathrm{ng} / \mathrm{ml}$ respectively, which is expected distribution of Prednisolone from the dendrimeric formulation. The presence of the higher amount of drug in the excretory organs at the $8^{\text {th }} \mathrm{hr}$ in the case of PEGylated dendritic formulations are tabulated in Table 1, demonstrates slow release of drugs from them. Similar results were observed in the case of lungs also. PEGylation have reduced the hepatic and bile accumulation of the drugs. These results agreed with the reports that the PEGylation of drug carriers such as nanoparticles and other polymer could improve their biodistribution characteristics of drugs [13].

\section{Conclusion}

By reducing non-specific interaction with biomolecules. Consequently PEGylation is also able to improve the biodistribution properties of the dendrimeric drug carriers such as PPI $5.0 \mathrm{G}$ dendrimers. The result of these studies has signified the ability of the drug loaded PEGylated PPI 5.0G dendrimer to alter the pharmacokinetics of drugs and it is efficacy to be used as sustained drug delivery system. 
Table 1 The Prednisolone level attained at various time intervals in different organ.

\begin{tabular}{|c|c|c|c|}
\hline \multirow{2}{*}{ Organ } & \multicolumn{3}{|c|}{$\begin{array}{r}\text { Concentration }(\mathrm{ng} / \mathrm{ml}) \text { at Different } \\
\text { Time Interval }\end{array}$} \\
\hline \multirow{2}{*}{ Liver } & A & $224 \pm 2.3$ & $129 \pm 4.1$ \\
\hline \multirow{2}{*}{ Kidney } & B & $122 \pm 1.6$ & $170 \pm 2.7$ \\
\hline \multirow{2}{*}{ Lung } & A & $303 \pm 2.6$ & $201 \pm 5.9$ \\
\hline \multirow{2}{*}{ Spleen } & B & $123 \pm 4.7$ & $90 \pm 7.2$ \\
\hline & A & $121 \pm 5.2$ & $82 \pm 4.3$ \\
\hline & B & $105 \pm 7.4$ & $274 \pm 6.5$ \\
\hline & B & $126 \pm 3.8$ & $258 \pm 3.4$ \\
\hline
\end{tabular}

\section{Acknowledgement}

The authors are thankful to Dr P. Balasubramaniyam, Executive Director, Shasun research centre, Chennai, India for synthesis of PPI dendrimer

\section{Conflict of Interest}

The authors worked in this research not showing any conflict of interest to publish this article. 


\section{References}

1 Griffin MR (1998) Epidemiology of nonsteroidal anti-inflammatory drug-associated gastrointestinal injury. Am J Med 104: 23S-29S.

2 Chi SC, Jun HW (1990) Anti-inflammatory activity of ketoprofen gel on carrageenan-induced paw edema in rats. J Pharm Sci 79: 974-977.

3 Lin SZ, Wouessidjewe D, Poelman MC, Duchone (1994) In vivo evaluation of indomethacin/cyclodextrin complexes gastrointestinal tolerances and dermal anti-inflammatory activity. D Int J Pharm 106: 63-67.

4 Chan TA (2002) Nonsteroidal anti-inflammatory drugs, apoptosis, and colon-cancer chemoprevention. Lancet Oncol 3: 166-174.

5 Jacobs J, Goldstein AG, Kelly ME, Bloom BS (1988) NSAID dosing schedule and compliance. Drug Intell Clin Pharm 22: 727-728.

6 Tomalia DA, Baker H, Dewald JR (1986) Dendritic macromolecules: synthesis of starburst dendrimers. Macromolecules 19: 2466-2468.

7 Stahn C, Löwenberg M, Hommes DW, Buttgereit F (2007) Molecular mechanisms of glucocorticoid action and selective glucocorticoid receptor agonists. Mol Cell Endocrinol 275: 71-78.
8 Karthikeyan R, Kumar PV, Koushik OS (2016) Dendrimeric Biocides - A Tool for Effective Antimicrobial Therapy. J Nanomed Nanotechnol 7: 359.

9 María Nella G, Elizabeth P, Claudio P, Jorge C, Verónica P, and Aquiles $A(2005)$ Determination of Prednisolone and Prednisone in Plasma, Whole Blood, Urine, and Bound-to-Plasma Proteins by High-Performance Liquid Chromatography. Journal of Chromatographic Science 43: 54-58

10 Beezer AE, King ASH, Martin IK, Mitchel JC, Twyman LJ, et al. (2003) Dendrimers as potential drug carrier, encapsulation of acidic hydrophobies within water soluble PAMAM derivatives. Tetrahedron Lett 59: 3873-80.

11 Devarakonda B, Hill RA, de Villiers MM (2004) The effect of PAMAM dendrimer generation size and surface functional group on the aqueous solubility of nifedipine. Int J Pharm 284: 133-140.

12 Asthana A, Chauhan AS, Diwan PV, Jain NK (2005) Poly(amidoamine) Dendritic Nanostructures for Controlled Sitespecific Delivery of Acidic Anti-inflammatory Active Ingredient. AAPS PharmSciTech 6: 536-542.

13 Kumar PV, Asthana A, Dutta T, Jain NK (2006) Intracellular macrophage uptake of rifampicin loaded mannosylated dendrimers. J Drug Target 14: 546-556. 